Список литературы:

1. Гущин А. Н. Базы данных: учебно-методическое пособие / А.Н. Гущин. - 2-е изд., испр. и доп. - М.; Берлин: Директ-Медиа, 2015. - 311 с.

2. Медведкова И.Е. Базы данных / И.Е. Медведкова, Ю.В. Бугаев, С. В. Чикунов; Министерство образования и науки РФ, ФГБОУ ВПО «Воронежский государственный университет инженерных технологий»; науч. ред. Г.В. Абрамов. - Воронеж: Воронежский государственный университет инженерных технологий, 2014. - 105 с.

\title{
Управление очередью в бюджетных учреждениях здравоохранения
}

\author{
Мелехова Е.Е., Демидова А.А., студенты, \\ Сибирский институт управления, \\ филиал Российской академии народного \\ хозяйства и государственной \\ службы при Президенте Российской Федерации, \\ 2. Новосибирск \\ E-mail: melekhova.ee@yandex.ru, \\ demidova200796@gmail.com
}

Научный руководитель: к.n.н., доцент Геращенко М.М.

В настоящее время теория массового обслуживания играет важную роль в анализе эффективности работы сотрудников и качестве предоставляемых услуг. Теория массового обслуживания или же теория очередей реализуется через наличие клиентов, вызовов, сигналов, места обслуживания и обработки, передачу. Теория очередей представляет собой раздел теории вероятности, где изучаются массовые обслуживания с помощью математических моделей [1].

Теория массового обслуживания (ТМО) изучает взаимосвязь между количеством каналов, производительностью, эффективностью числа заявок, и выбора наилучшего пути управления различными процессами [1]. Теория очередей (Queuing theory) описывает функционирование сложных систем массового обслуживания, находящихся под воздействием значительного числа неупорядоченных случайных событий, с целью повышения эффективности (увеличения пропускной способности, уменьшения времени обслуживания, сокращения затрат и т.п.) [2].

Практически теорию очередей можно применять в разных сферах, таких как банковское обслуживание клиентов, таможенные терминалы, городское движение транспорта, справочные центры, многофункциональные центры. В данной статье будет рассмотрено применение теории очередей в бюджетных медицинских учреждениях.

У большинства жителей России посещение бюджетного учреждения здравоохранения ассоциируется с огромной потерей времени в очереди. Считаем необходимым решить эту проблему. Качество обслуживания гражданами оценивается, как неудовлетворительное.

Как сделать так, чтоб очередей в поликлиниках не было? Избежать таких ситуаций, когда человек находится в очереди около часа или не попадает на прием к 
врачу совсем? Применим теорию очередей, которая поможет определить, сколько сотрудников необходимо нанять и как распределить клиентов.

В настоящее время терапевты прикреплены к определенному участку. Записаться заранее можно только на первый прием, но эта запись, в большинстве случаев, является условной (так как приходят пациенты и повторно и в третий раз). Время записи и время фактического приема не совпадает, у кабинета возникает живая очередь. Сделав наблюдение и рассчитав показатели с помощью табличного процессора Excel, были получены следующие данные (см. табл.1).

Таблица 1

Расчет загрузки терапевтов на основе наблюдения

\begin{tabular}{|l|l|l|l|l|l|l|l|l|l|l|}
\hline Врач & $\mathrm{N}$ & $\tau_{\mathrm{C}}$ & $\lambda$ & $\rho$ & КВп & KBc & $\mathrm{Wq}$ & $\mathrm{W}$ & $\mathrm{Lq}$ & $\mathrm{L}$ \\
\hline $\begin{array}{l}\text { Терапевт } \\
\text { №1 }\end{array}$ & 16 & 17,187 & 0,067 & 1,146 & 0,449 & 0,169 & $\infty$ & $\infty$ & $\infty$ & $\infty$ \\
\hline $\begin{array}{l}\text { Терапевт } \\
\text { №2 }\end{array}$ & 17 & 16,235 & 0,071 & 1,285 & 0,797 & 0,188 & $\infty$ & $\infty$ & $\infty$ & $\infty$ \\
\hline $\begin{array}{l}\text { Tерапевт } \\
\text { №3 }\end{array}$ & 12 & 17,500 & 0,050 & 0,875 & 0,667 & 0,176 & 29,139 & 46,639 & 1,457 & 2,332 \\
\hline
\end{tabular}

$\mathrm{N}$ - количество пациентов, которые пришли на прием в день наблюдения. Как видно из таблицы в данный день к терапевтам пришло разное количество пациентов. К терапевту №2 на самом деле пришло 20 пациентов, но 3 посетителя, увидев большую очередь, не стали ждать и ушли.

$\tau \mathrm{C}$ (среднее время обслуживания), среднее значение времени обслуживания каждого клиента. В Excel используется формула СРЗНАЧ. Все терапевты работают примерно с одинаковой скоростью.

$\lambda$ (средняя частота обращений, клиентов в минуту), частное от деления количества пациентов у одного терапевта и временем работы этого терапевта. Терапевты в данный день работали 230 минут.

$\rho$ (средний коэффициент Загрузки работника) $=\tau C^{*} \lambda$. Мы видим, что загруженность первого и второго терапевта слишком велика. Они не смогут принять всех пациентов в данный день или же им придется переработать.

КВП (коэффициент вариативности прибытия) - величина, характеризующая вариативность процесса обращений. Если он равен нулю, то для системы характерны детерминированные обращения, если равен 1 - абсолютно случайные (независимые) обращения, если меньше 1 - обращения по расписанию или обращения с негативной корреляцией, если больше 1 - всплески обращений или обращения с позитивной корреляцией. Результат получается от разницы деления стандартного отклонения интервала времени между последовательными прибытиями на средний интервал времени между прибытиями пациентов. В данном случае коэффициент вариативности прибытия находится в интервале от нуля до единицы, что означает, что пациенты в поликлинику приходят в разное, независимое друг от друга время. Есть те, кто записывался на время и те, кто хочет попасть на прием в порядке живой очереди. Так и было при наблюдении: в одно время у кабинета был 1 или 2 человека, в другое создавалась очередь из 5 человек.

КВс (коэф. Вариативности обслуживания) - величина, характеризующая вариативность процесса обслуживания. Для ее определения необходимо среднеквадратичное отклонение распределения времени обслуживания поделить на 
среднее время обслуживания. В нашем случае вариативность обслуживания небольшая, но она есть, так как проблемы у пациентов разные и диагностика занимает неодинаковое время.

Wq (среднее время ожидания в очереди), данная величина, можно сказать, показывает сколько примерно простоит пациент, если пойдет к врачу. Так как у первого и второго терапевта загрузка большая, есть возможность, что клиент придет, простоит в очереди, но так и не попадет к врачу. Wq рассчитывается по формуле:

$$
\mathrm{Wq}=\tau \mathrm{C} \times \frac{\mathrm{p}}{1-\mathrm{p}} \times \frac{1}{2} \times\left[\mathrm{KB}^{2}+\mathrm{KBc}^{2}\right]
$$

W показывает сколько в среднем клиент находится в поликлинике (ожидание и обслуживание). По расчётам получается, что клиенты терапевта №1 и терапевта №2 могут так и не попасть на прием.

Lq (среднее количество клиентов в очереди) и L (среднее количество клиентов в поликлинике (в очереди и в обслуживании)) вычисляются путем умножения средней частоты обращений $\lambda$ на Wq и W соответственно. У терапевта №1 и №2 посетителей слишком много.

Таким образом только загрузка терапевта № 3 приемлемая. При этом очень высокий коэффициент вариативности прибытия пациентов $(0,67)$, в связи с чем мы видим значительное среднее время ожидания и обслуживания.

Для того, чтобы изменить такой отрицательный результат, можно предложить поликлинике не распределять пациентов строго по участкам. Для эффективного использования времени работы терапевтов и качественного обслуживания пациентов необходимо ввести электронную очередь. Данный программно-аппаратный комплекс позволит формализовать и оптимизировать управление потоком посетителей. Все пациенты будут распределятся к терапевтам в зависимости от их загрузки. Рассмотрим пример объединения очередей к трем терапевтам в одну очередь (см. табл. 2).

Таблица 2

Объединенная очередь к трем терапевтам

\begin{tabular}{|l|l|l|l|l|l|l|l|l|l|l|}
\hline $\mathrm{S}$ & $\mathrm{N}_{\text {объед }}$ & $\tau_{\mathrm{C}}$ & $\lambda_{\text {объед }}$ & $\rho$ & КВП & КВc & $\mathrm{Wq}$ & $\mathrm{W}$ & $\mathrm{Lq}$ & $\mathrm{L}$ \\
\hline 3 & 45 & 16,911 & 0,187 & 1,057 & 0,848 & 0,177 & $\infty$ & $\infty$ & $\infty$ & $\infty$ \\
\hline
\end{tabular}

\section{S- Количество терапевтов.}

Загрузка стала ниже, чем у отдельно взятого терапевта №1 и №2, но она осталась слишком большой. То есть если бы в поликлинику пришли 45 клиентов, то три терапевта принимали бы их 105,7 \% своего рабочего времени, что физически невозможно. Мощности трех терапевтов недостаточно для того, чтобы обслужить всех посетителей. Если добавить одного обслуживающего терапевта, то получится следующее (см. табл. 3). 
Объединенная очередь к 4 терапевтам

\begin{tabular}{|c|c|c|c|c|c|c|c|c|c|c|}
\hline $\mathrm{S}$ & $\begin{array}{c}\mathrm{N}_{\text {объе }} \\
\text { д }\end{array}$ & $\tau_{\mathrm{C}}$ & $\lambda_{\text {объед }}$ & $\rho$ & КВп & $\mathrm{KBc}$ & $\mathrm{Wq}$ & $\mathrm{W}$ & $\mathrm{Lq}$ & $\mathrm{L}$ \\
\hline 4 & 45 & 16,911 & 0,187 & 0,793 & 0,848 & 0,177 & 4,631 & 21,542 & 0,868 & 4,039 \\
\hline 4 & 48 & 16,911 & 0,200 & 0,845 & 0,848 & 0,177 & 7,147 & 24,058 & 1,429 & 4,812 \\
\hline
\end{tabular}

Четыре терапевта - оптимальное решение. Если в поликлинику придет 45 человека, они смогут на должном уровне всех принять. Считается, что коэффициент загрузки, равный 0,8, является балансом между эффективной работой специалиста и достойным качеством обслуживания. Время ожидания в очереди составляет 4,6 минут, что вполне приемлемо. Четыре терапевта смогли бы принять и тех трех пациентов, которые не стали дожидаться приема.

Итак, необходим еще один терапевт. Кроме того, учитывая значительную вариативность прибытия пациентов, для возможности принять всех пациентов и сокращения времени ожидания возможно объединить их в одну очередь.

Но для того, чтобы принимать управленческие решения такого характера, необходим более полный анализ процесса. Так как каждый день ситуация разная. На количество пациентов, обращающихся в поликлинику, может влиять сезон, инфекция. То есть появление человека в поликлинике предугадать нельзя. Поэтому необходимо установить систему управления электронной очередью, благодаря которой анализ статистических данных и работа с отклонениями (вариативностью процессов) возможны в реальном времени. Станет возможным установить, когда возникает очередь и оперативно применять меры по ее устранению.

\section{Список литературы:}

1. Грибакова Я.Ю., Визняк Е.М., Дышловой И.Н. Теория массового обслуживания // Инновационные научные исследования: теория, методология, практика сборник статей победителей V Международной научно-практической конференции. 2017. URL: http://elibrary.ru/download/elibrary_27660524_13890206.pdf (дата обращения: 26.02.2017).

2. Осипов Л.А. Алгоритм решения проблемной задачи теории очередей // Журнал Наука и техника транспорта. 2009. № $4 . \quad$ URL: http://elibrary.ru/download/elibrary_14339195_38884103.pdf (дата обращения: 26.02.2017). 